\title{
TRUCOS EN URETRA
}

\author{
Carlos Rioja Sanz ${ }^{1}$, José Vicente Rodríguez ${ }^{2}$ y Marcelino G onzález Martín
}

${ }^{1}$ Servicio de Urología Hospital Universitario M iguel Servet Zaragoza.

${ }^{2}$ Fundación Puigvert Barcelona. Barcelona.

${ }^{3}$ Servicio de Urología Hospital Juan C analejo. La Coruña. España.

\section{ÍN DICE/ RESUMEN}

1. No pasa la sonda posturetrotomía ¿qué hacer?. C. Rioja Sanz.

2. N o se visualiza la luz uretral ¿qué hacer?.

C. Rioja Sanz.

3. Se ha perdido la luz o continuidad uretral ¿qué hacer?.

J. Vicente Rodríguez.

4. Rotura uretral ¿solución endourológica?.

M. González Martín.

Palabras clave: Trucos en uretra. Sonda uretral. Luz uretral. Rotura uretral.

\section{Carlos Rioja Sanz}

Servicio de Urología

Hospital Universitario M iguel Servet

Pso. Isabel La Católica, 1-3

50009 -Zaragoza (España)

\section{NO PASA LA SONDA POSTURETROTOMÍA ¿QUÉ HACER?}

C. Rioja Sanz.

Una vez seccionada o dilatada la estenosis es posible que no nos pase la sonda uretral, probablemente debido a que persiste cierto grado de anfractuosidad uretral o que la luz conseguida no es suficientemente amplia. En nuestra sistemática siempre realizamos la sección o dilatación uretral con un alambre guía de seguridad, bien colocado previamente al corte si la luz es franqueable 0 al finalizar el mismo. Esta guía nos va a permitir colocar coaxialmente la sonda con facilidad. Es necesario colocar una sonda de punta abierta ( ya disponibles de fábrica) o seccionar la punta comprobando posteriormente que el balón permite ser hinchado. Como la fricción de la sonda sobre la guía suele ser intensa es importante lubricar bien la uretra y la guía para que deslice la sonda (las sondas de silicona tienen un eleva do grado de fricción). 0 tro truco en cateterismos muy complejos es reintroducir el endoscopio bajo visión hasta alojarlo en vejiga. Se deja exclusivamente la vaina y a su través se introduce una sonda rígida, tipo N elaton, no autoestática, es decir sin balón, a la que cortamos el pabellón para poder sacar la vaina del endoscopio dejando alojada la sonda que se sujeta al prepucio con puntos. En el mercado existe un aditamento para el uretrotomo, consistente en una medica caña metálica sobre la que discurre la vaina del mismo. Una vez extraída la vaina queda alojada la media caña que permite pasar una sonda tipo Foley. 


\section{NO SE VISUAUZA LA LUZ URETRAL ¿QUÉ HACER?}

C. Rioja Sanz.

En condiciones normales, mientras el paciente con una estenosis realice las micciones por vía uretral, la luz de la misma, aunque sea mínima, permite su cateterización con un alambre guía y de esta manera proceder al tratamiento de elección. Una circunstancia frecuente es tratar una estenosis de uretra a un paciente al que previamente se le ha realizado una derivación urinaria suprapúbica. La desfuncionalización de la uretra comporta un cierre completo de la misma siendo en estos casos muy difícil o imposible ver la luz uretral. Intentar abrirse paso a ciegas a través de la espongiofibrosis que rodea a una estenosis de uretra es sumamente arriesgado y en todo punto no aconsejable por la posibilidad de perder la dirección correcta y producir una grave falsa vía de difícil resolución o lesionar los cuerpos cavernosos.

En estos casos disponemos de algunas maniobras que nos ayudan a orientarnos en la dirección correcta. Se rellena la vejiga por vía suprapúbica (a través de una punción con aguja fina o una talla) con una solución de suero salino y azul de metileno o patent-blue. Aumentando la presión abdominal o invi-

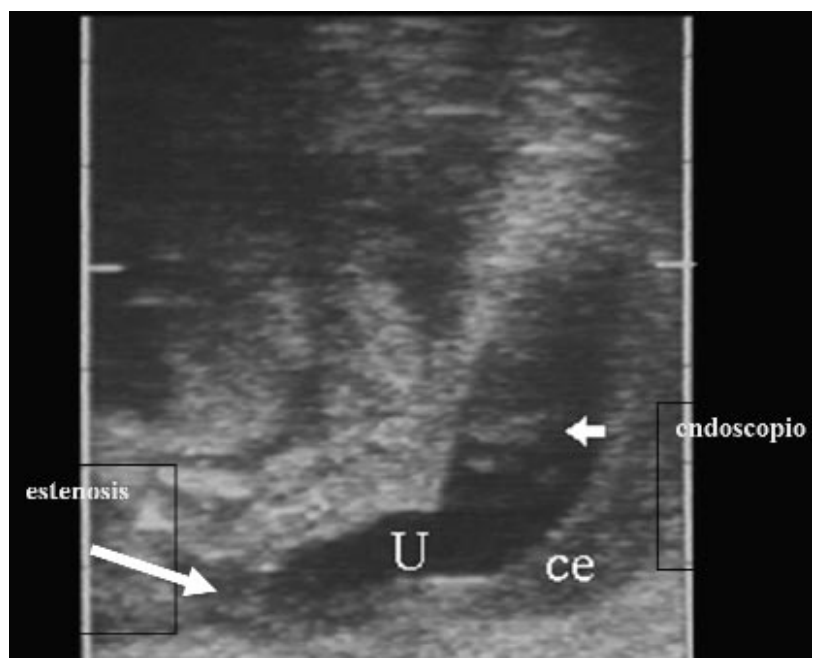

FIG URA 1. Podemos observar la uretra bulbar con la sombra producida por el endoscopio, la curva uretral en su entrada al periné y la facilidad de perforar el cuerpo esponjoso (ce) si equivocamos la dirección.

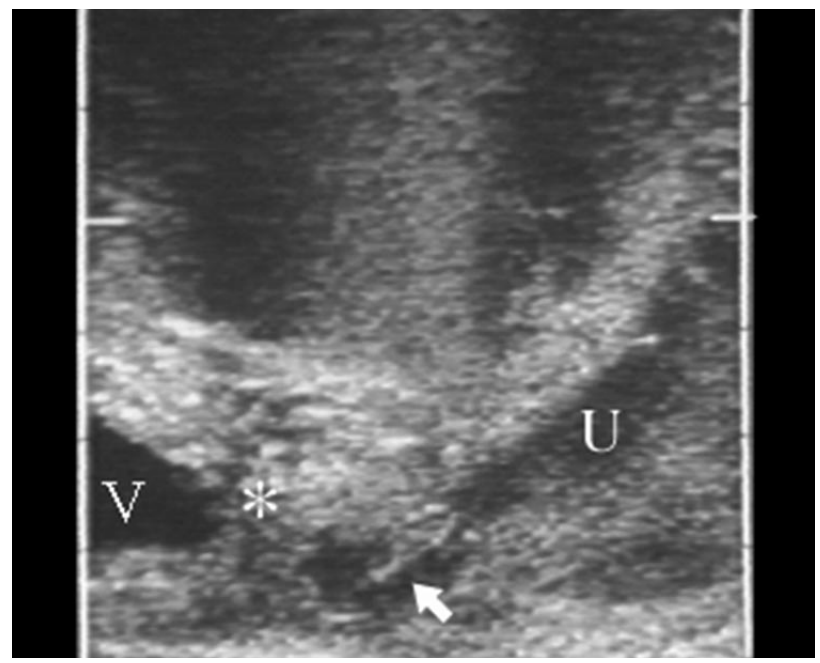

FIG URA 2. La flecha señala el cuchillete de Sachse pudiéndose observar la cavidad vesical (V) y el callo fibroso de una esclerosis de celda $(*)$. La tendencia natural del corte sería la de ir en situación subtrigonal.

tando al paciente a realizar esfuerzos miccionales si está bajo anestesia raquídea, podemos apreciar el paso de un hilo de colorante que nos ayuda a conocer la dirección de la luz uretral. Siempre que sea posible es recomendable intentar pasar una guía por

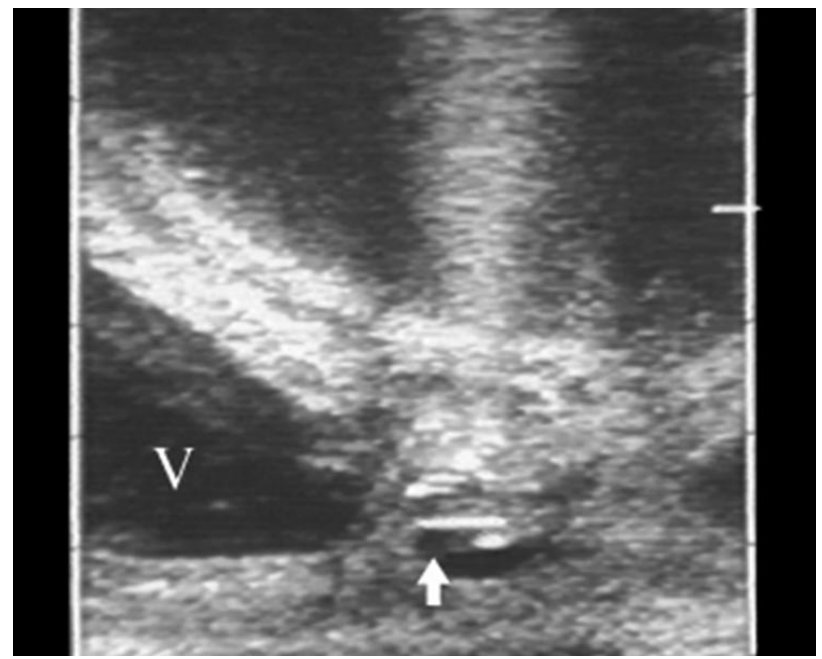

FIG URA 3. Corregida la dirección del endoscopio, mediante basculación del mismo se aprecia la correcta dirección del corte. En la imagen se aprecia con nitidez, señalado por la flecha, el cuchillete. 


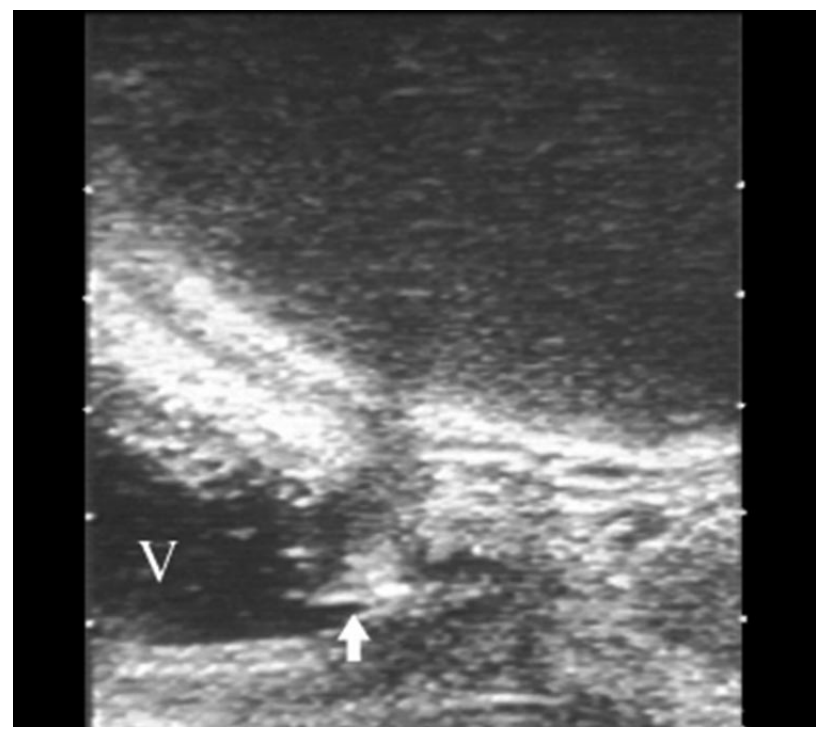

FIG URA 4. El cuchillete ya ha superado la estenosis, penetrando en la luz proximal. El gesto quirúrgico es mixto, endoscópico y ecográfico.

el punto que aparece el colorante, antes que realizar cortes a ciegas. Guías de tipo Terumo, con una propiedad extraordinaria para sobrepasar zonas estenóticas y anfractuosas nos facilitan extraordinariamente el reconocimiento de la anatomía uretral.
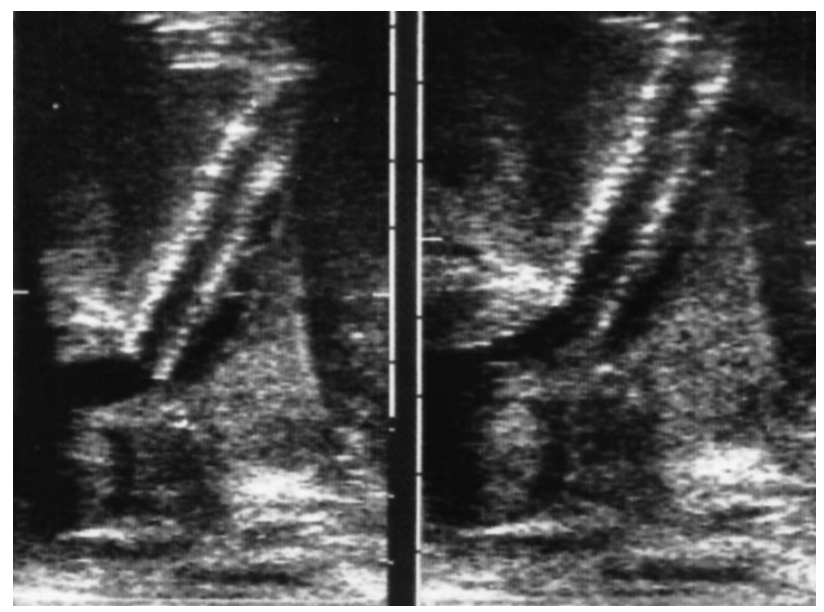

FIG URA 5. Podemos observar en esta imagen la nitjdez con que se observa el endoscopio en la luz uretral y la importancia de la dirección-orientación del corte donde fácilmente se puede realizar una falsa vía.
En nuestra experiencia, tanto para "recanalizar" una estenosis de uretra como una esclerosis de celda o cuello vesical infranqueables, preferimos apoyarnos en el uso del transductor ecográfico transrectal. La ecografía transrectal nos permite perfectamente visualizar la luz uretral proximal y distal, la zona estenótica y la dirección que debemos seguir para recanalizar la uretra. Es de destacar que en todos los casos en que hemos realizado esta maniobra, la intuición quirúrgica sobre donde trascurría la continuidad uretral nos equivocaba, debiendo siempre de cambiar la dirección del corte como podremos comprobar en las imágenes adjuntas. Con este "truco" podemos ver los dos cabos de la luz uretral e ir avanzando lentamente con el cuchillete de Sachse, que se aprecia perfectamente en la pantalla del ecógrafo, hasta encontrar la zona proximal. La técnica se realiza entre dos cirujanos, uno que maneja el ecógrafo y el otro el endoscopio, perfectamente coordinados.

\section{SE HA PERDIDO LA LUZ O CONTINUIDAD URETRAL: ¿ QUÉ HACER?}

J. Vicente Rodríguez.

Reconocer/ recuperar la luz uretral "perdida" - recuperar la continuidad del conducto uretral, es necesario tanto al inicio de la intervención programada como en casos de "sellado" uretral por patologías ya conocidas y también al finalizar el procedimiento ante la dificultad de paso de la sonda uretral.

En cualquiera de estas situaciones necesitamos recurrir a diferentes trucos endourológicos.

\section{1.- Trucos en actuación inmediata:}

- Al inicio de la uretrotomía se pasa a través del orificio estenótico un catéter $405 \mathrm{Ch}$. hasta la cavidad vesical a tra vés del orificio estenótico; a veces ello no es posible porque no avanza el catéter o porque hay más de un orificio en la "pared" estenótica (casi siempre por falsas vías preteritas) y todos parecen ciegos. En estos casos es conveniente colocar una cistostomía hipogástrica e instilar suero salino con índigo carmil concentrado; haciendo presión hipogástrica manual y cerrando la irrigación del uretrótomo, se ve fluir líquido azulado por el orificio correcto, permitiéndonos pasar el catéter a vejiga (goteo azulado por el catéter). (1) 
- En casos de recanalización endoscópica inmediata (5-6 días de reposo post traumatismo) el paciente lleva siempre catéter suprapúbico; a su través se coloca una guía metálica que permite la colocación de un tubo de A mplat 24 ch. Tras las maniobras de dilatación del trayecto, a través de él, se introduce un cistoscopio rígido o flexible hasta uretra posterior y se pasa una guía metálica ( se insinúa unos 2-3 centímetros). Por uretra se pasa el panendoscopio hasta alcanzar la uretra membranosa; se aprehende la guía metálica y se exterioriza por meato uretral y en el se enhebra sonda 18-20 Ch que se mantendrá como tutor mes 0 mes y medio. (2)

\section{2.- Trucos en actuación diferida:}

En esto casos la causa y características de la estenosis no son conocidas: esclerosis celda-cuello post cirugía de HBP, esclerosis uretra posterior post prostatectomía radical; estenosis amplia tras dos / tres meses de traumatismo ct. En todos estos casos el paciente es portador de sonda de cistostomía; ésta nos servirá para pasar guía y dilatadores hasta poder colocar un tubo de Amplatz o trocar de Hasson.

Las maniobras endourológicas siempre serán combinadas : anterógrada y retrógrada; el alineamiento del instrumento transvesical y transuretral se facilita con ayuda de ecografía o la utilización del

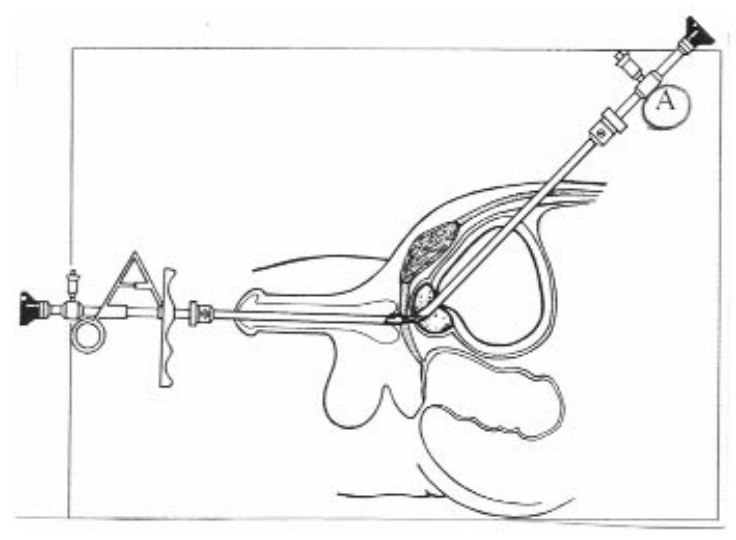

FIG URA IA. Citoscopio rígido o flexible que permite la exploración de la uretra proximal o la posibilidad de realizar un corte transuretral anterógrado "siguiendo la luz" para encontrar e incidir la uretra lesionada (3).
Arco en C. El instrumento transuretral siempre será el uretrótomo óptico o el panendoscopio, pero el transvesical (a través de A mplatz o Hasson) puede ser como se refleja en las Figuras $1 \mathrm{~A}$ y $1 \mathrm{~B}$.

\section{3.- Trucos al finalizar la actuación endoscópica:}

- Después de realizar la uretrotomía endoscópica, si no es posible posicionar correctamente la sonda uretral, podemos realizar la siguiente maniobra: colocar externa a la vaina del uretrótomo o panendo, la vaina semicircular de Storz; una vez introducidos bajo visión ambos hasta cavidad vesical, se retira el instrumento y queda el canal de la vaina semicircular que permite colocar la sonda (5).

- En casos de estenosis complejas en que se haya realizado la vía combinada, es útil el paso de una guía metálica vascular y a su través un catéter uretral que

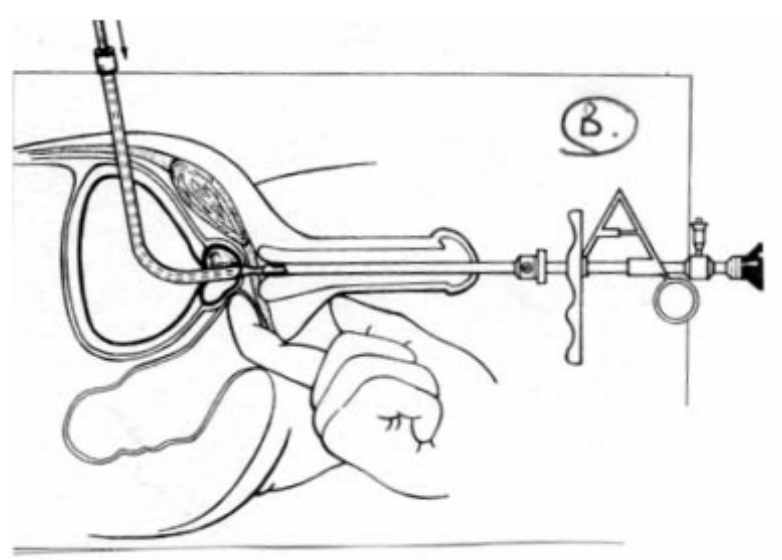

FIG URA 1B. Beniqué curvo que se introduce por vía suprapúbica hasta el cabo de la uretra proximal oblitearada (se ayuda con tacto rectal), ofreciendo al presionar sobre la uretra un punto donde cortar por vía transuretral (con el cuchillete frio o Collins). $N$ osotros hemos utilizado el mismo beniqué pero recubierto de teflón como aislante excepto en los dos extremos; en uno de ellos (el externo en "palometa")

se conecta con el electrobisturí y actúa como electrodo indiferente. Por vía transuretrtal retrógrada se pasa a través del panendoscopio un electrodo tipo Bugbee y alimentarlo eléctricamente, se crea un arco eléctrico entre el electrodo uretral y el extremo no aislado del beniqué. Con una ligera presión se facilita la recanalización uretral. (4). 
se colocará retrógradamente hasta la cavidad vesical; este se exteriorizará por el meato uretral y nos servirá de guía para la introducción de una sonda vesical (2).

\section{BIBUOGRAFÍA RECOMENDADA}

1. AUWATER, H.L.: "The history of urethral stricture". Br. J. Urol., 15: 39, 1943.

2. GUILLÉ, F.; CIPOLLA, R.: "Endoscopic recanalization or membranous urethral disruption injuries". Reconstructive surgery of lower genito-urinary tract in adults. Colleen y Masson SIU reports, ISIS Medical Oxford, 1995.

3. LEONARD, M.P.; EUTAGE, J.; PÉREZ, R. y cols.: "Endoscopic management of urethral stricture. "Cut to the Light” procedure". Urology, 35: 117, 1990.

4. ROSALES, A.; VICENTE, J.: "Cirugía endoscópica de cuello y uretra". Tratado de endoscopia J. Vicente. Ed. Pulso, 6: 413, 1996.

5. MITCHELL, J.P.: "The endoscopic surgery of urethral stricture: urethronomy". Endoscopic operative urology. Wright. PSG. Bristol. London. Boston, 177, 1981.

\section{ROTURA URETRAL ¿SOLUCIÓN ENDOU- ROLÓGICA?}

M. González Martín.

La rotura traumática de la uretra membranosa o bulbar plantea serias dificultades y su manejo y tratamiento es controvertido. $\mathrm{No}$ existe un tratamiento universalmente aceptado.

Las principales opciones son:

1. Cirugía abierta, precoz con realineamiento,

2. Reanastomosis uretral precoz,

3. Uretroplastia demorada pasados tres meses,

4. Tratamiento endoscópico - endourológico precoz.

La experiencia con tratamiento endoscópicoendourológico precoz, entre la primera y segunda semana es escasa, pero los resultados comunicados merecen la pena ser tenidos en cuenta aún aceptando serios inconvenientes:

1. No siempre es posible realizarla,

2. La estenosis posterior ocurre en alto porcentaje de casos.
Sus ventajas son:

1. Cirugía mínimamente agresiva con posibilidad de alta precoz con sonda uretral,

2. Esta cirugía no aumenta los porcentajes de impotencia 0 incontinencia causados por la lesión traumática.

A nalicemos el primer problema. No siempre es posible realizar el tratamiento.

El paciente tiene sonda de talla que como es lógico fue el tratamiento de urgencia. Pasamos el cistoscopio de forma retrógrada y a nivel de la lesión no se visualiza luz uretral. Se ha perdido la continuidad de la uretra a nivel de la lesión. No existe sangrado activo pero en su lugar hay coágulos más o menos organizados.

La primera maniobra es intentar pasar a través de ellos una guía recta, con extremo blando. Con un arco en $\mathrm{C}$ de radioscopia podemos seguir la progresión o no de la guía. Si la lesión es corta, localizada y sin desplazamiento de los extremos uretrales, la guía puede pasar a vejiga directamente. Es el mejor de los casos. A continuación, sobre la guía, retirado el cistoscopio, pasamos un balón de dilatación, lo colocamos sobre la zona de rotura. Dilatamos cuidadosamente esta zona. Estas maniobras son seguidas mediante visión fluoroscópica. Finalmente retiramos el catéter de balón y sobre la guía pasamos una sonda de Foley con el extremo perforado. La dejaremos cuatro semanas en la idea de que se produzca epitelización de la zona de la rotura. (Figuras 1, 2, 3)

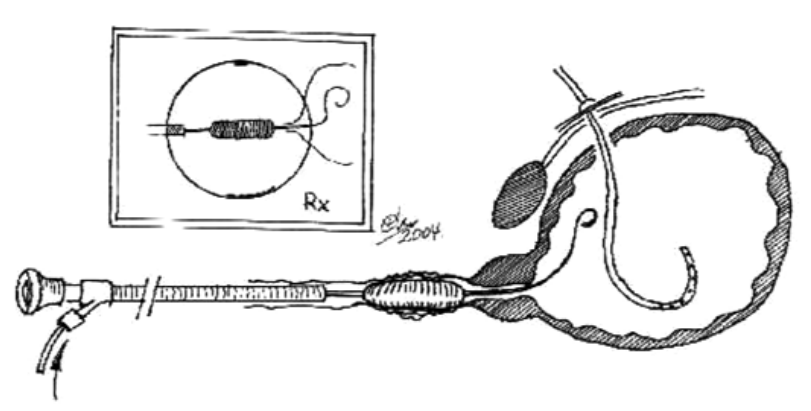

FIG URA 1. Esquema de dilatación ureteral retrógrada. Esquema mostrando paso de la guía a través de la zona de rotura con balón de dilatación. Detalle de imagen fluoroscópica. 


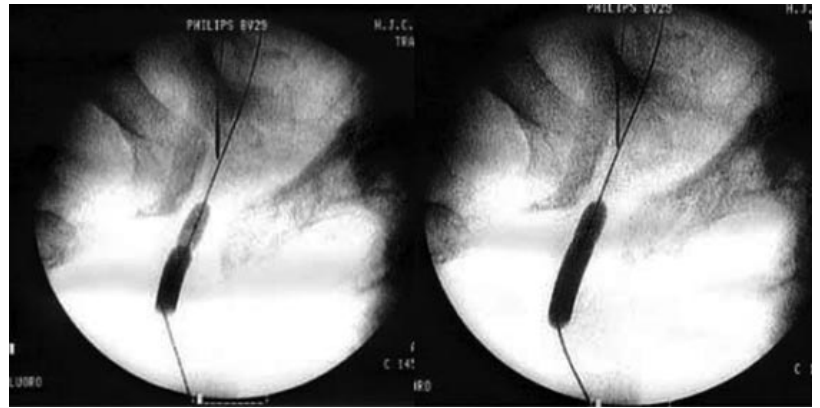

FIG URA 2. Imágenes fluoroscópicas de dilatación uretral retrógrada.

a) Inicio de dilatación

b) Final de dilatación uretral.

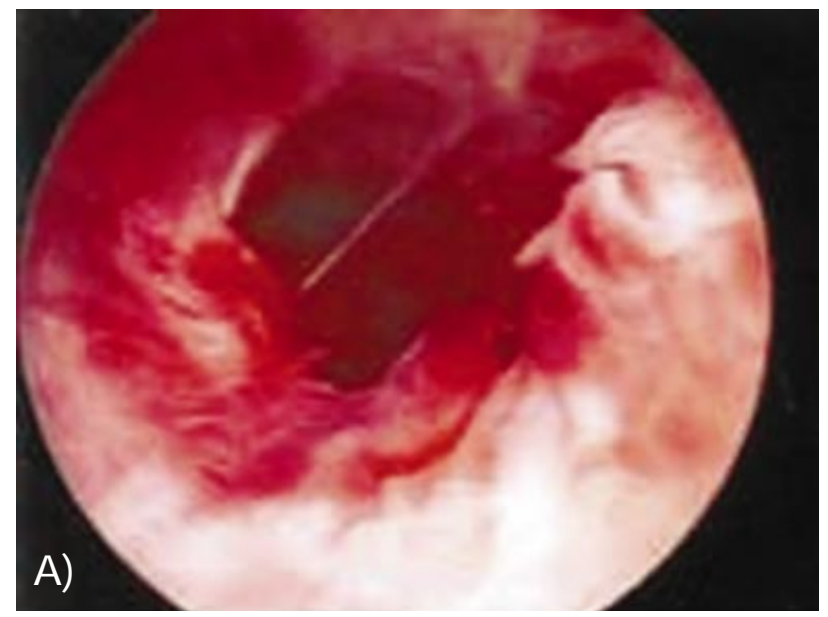

FIG URA 3A. Rotura de uretra bulbar. Rotura uretral.

2) Pasamos ahora el uretroscopio vía uretral retrógrada, con óptica de 0 grados, con una pinza de cuerpos extraños. Progresamos hasta la zona de rotura y mediante control fluoroscópico podemos coger la guía introducida a través el cistoscopio flexible vía cistostomía. (Figura 5)

3) Extraemos la guía por uretra y finalmente realizamos la maniobra de dilatación y colocación de la sonda de Foley como describimos anteriormente.

En caso de que esta maniobra sea también fallida, dejamos la cistostomía y la estenosis será reparada quirúrgicamente pasados tres meses.

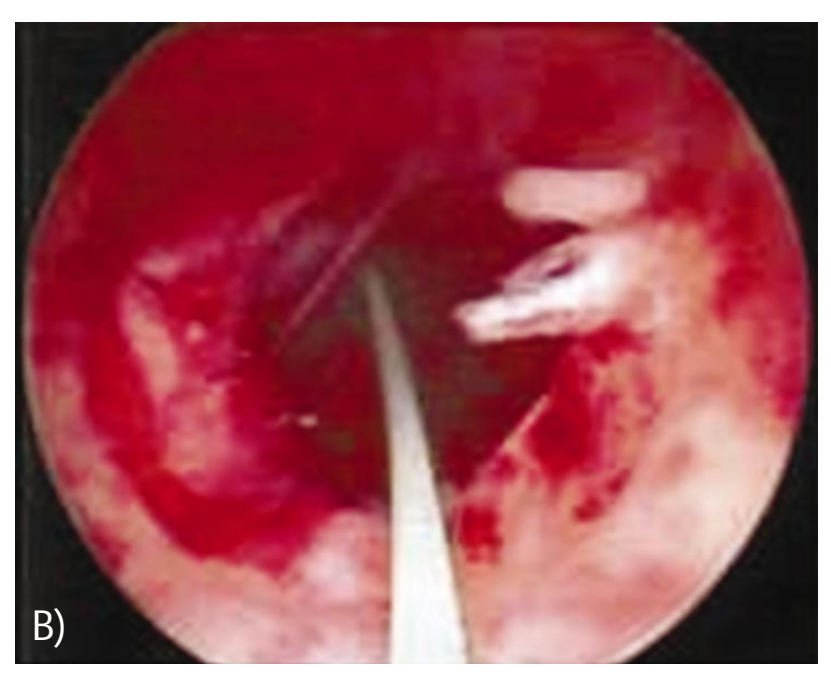

FIG URA 3B. Rotura de uretra bulbar. Cateterismo uretral retrógrado con guía metálica.

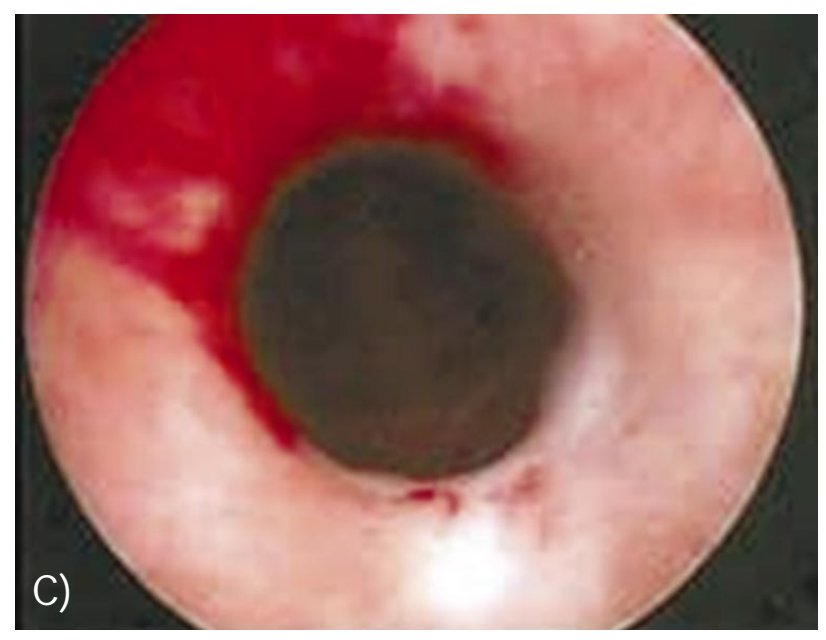

FIG URA 3C. Rotura de uretra bulbar. Control endoscópico a los 6 meses. 


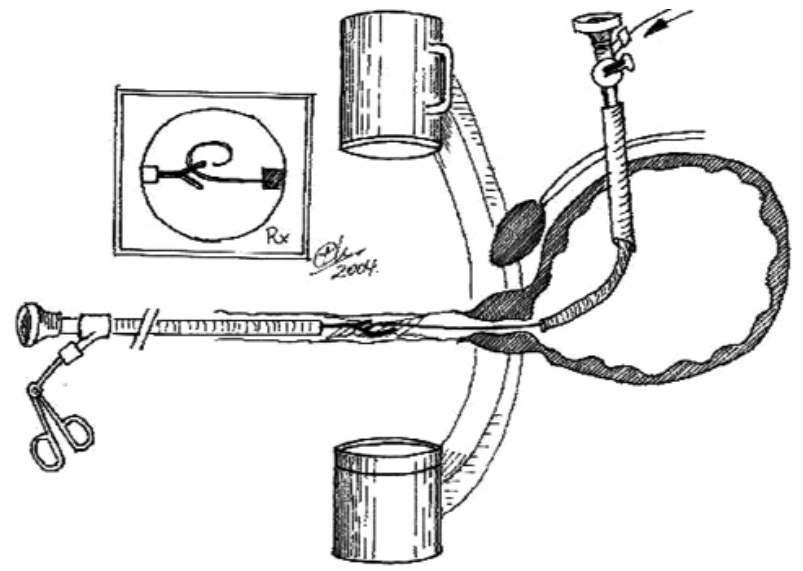

FIG URA 4. Esquema cateterismo a nterógrado. Manejo endoscópico-fluoroscópico de rotura uretral. Introducción de guía en uretra, vía anterógrada (a través de vejiga): Extración de guía metálica por uretra vía retrógrada. Control fluoroscópico.

\section{Comentarios}

Todos los procedimientos tienen una incidencia de complicaciones no despreciables. M.M. Koraitim comunica su propia experiencia de 100 pacientes con fractura de pelvis y rotura uretral y a la vez realiza una amplia revisión de 771 pacientes. La cistotomía realizada como tratamiento único de urgencia conlleva el $97 \%$ de estenosis posterior, el $4 \%$ de incontinencia y el $19 \%$ de impotencia. Si se realiza realinea miento quirúrgico primario la estenosis a parece secundariamente en el $53 \%$, la incontinencia en el $5 \%$ y la impotencia en el $36 \%$. La sutura primaria conlleva $49 \%$ de estenosis, $56 \%$ de impotencia y $21 \%$ incontinencia. Concluye, la cistostomía suprapúbica esta indicada en rotura incompleta de uretra con ligera separación uretral y paciente inestables. También en cirujanos con poca experiencia. El realinamiento primario no esta indicado si hay amplia separación de extremos uretrales o se asocia lesión de cuello de vejiga o recto. La sutura primaria no es recomendable en ninguna situación. (1)

G.D. W ebster llega a conclusiones parecidas en la revisión de 538 pacientes. La cistostomía y cirugía tardía conlleva $100 \%$ de estenosis, $11,6 \%$ de impotencia y $1,7 \%$ de incontinencia. Si se practica realineamiento quirúrgico primario, la estenosis posterior ocurre en el $69 \%$, la impotencia en el $44 \%$ y la incontinencia en el $20 \%$ (2). Corriere JN comunica su experiencia de uretroplastia bulbouretral tardía en 58 roturas (Reparación via perineal). Tiene $3 \%$ de lesión rectal, $5 \%$ de cirugía repetida y $32 \%$ precisan uretrotomía y/o dilatación. Al año $72 \%$ de buenos resultados. Alrededor de la mitad de los pacientes, tienen impotencia. (3)

El segundo problema que indicábamos con la técnica endoscópica endourológica, es la frecuente estenosis de aparición tardía. Entre el 40 y $50 \%$ de los
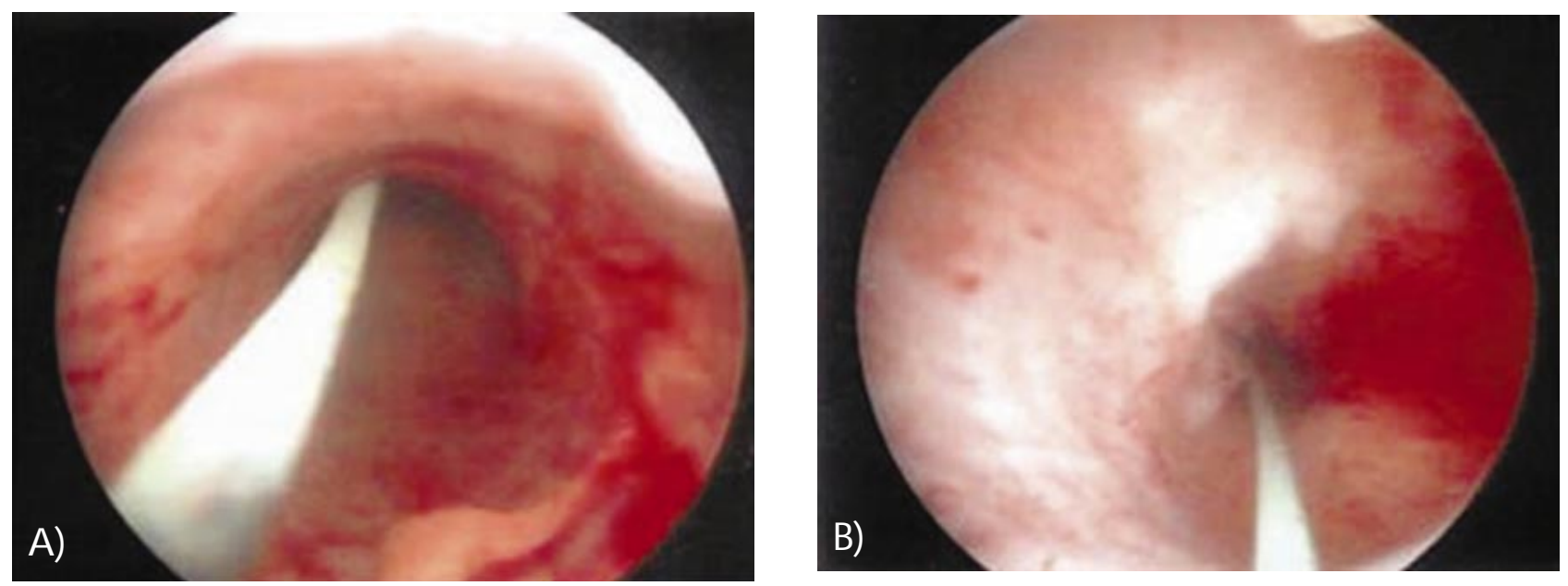

FIG URA 5. Cateterismo Anterógrado.

A) Cateterismo uretral anterógrado, visión endoscópica del veru montanum.

B) Imagen endoscópica de la zona estenótica de uretra, extrayendo guía metálica. 
casos, estos pacientes precisan al menos una uretrotomía y en un $10 \%$ cirugía correctora, uretroplastia (510). El realineamiento fluoroscópico precoz es un metodo efectivo de tratamiento para las lesiones severas traumaticas de la uretra (4-10), con alta posibilidad de precisar una uretrotomía posteriormente, sin a umentar la incidencia de impotencia e incontinencia. En cualquier caso, el fracaso de esta técnica no compromete el resultado de la uretroplastia secundaria.

Cuando la estenosis se ha producido y decidimos realizar uretrotomía, practicamos el corte con asa de Collins, seccionando el anillo estenótico y no siempre a las doce horas del horario citoscópico, sino en la zona que estenosa.

¿Cómo intentar prevenir la estenosis? En nuestra experiencia, el paciente en consulta externa es instruido y entrenado para que se realice autodilatación, primero cada dos semanas durante dos meses y posteriormente cada mes hasta completar seis meses.

La autodilatacion se hará con profilaxis de un comprimido de Ciprofloxacino, inyección de xilocaina en la uretra y dilatación con dilatador uretral hidráulico de Rush. El paciente lo acepta de buen grado en la idea de prevenir una cirugía abierta.

\section{BIBUOGRAFÍA RECOMENDADA}

1. KORAITIM, M.M.: "Pelvic fracture urethral injuries: the unresolved controversy". J. Urol. 161: 1433, 1999.

2. WEBSTER, G.D.; MATHES, G.L.; SELLI, C.: “ Prostatomembranous urethral injuries: a review of the literature and a rational approach to their management”. J. Urol., 130: 898, 1983.

3. CORRIERE, J.N.: "1-Stage delayed bulboprostatic anastomotic repair of posterior urethral rupture: 60 patients with 1 year follow-up". J. Urol., 165: 404, 2001.

4. LONDERGAN, T.A.; GUNDERSEN, L.H.; VAN EVERY, M.J.: "Early fluoroscopic realignment for traumatic urethral injuries". Urology, 49: 101, 1997.

5. TOWLER, J.M.; EISEN, S.M.: "A new technique for the management of urethral injuries". Br. J. Urol., 60: 162, 1987.

6. COHEN, J.K.; BERG, G.; CARL, G.H. y cols.: "Primary endoscopic realignment following posterior urethral disruption”. J. Urol., 146: 1548, 1991.

7. MOUDOUNI, S.M.; PATARD, J.J.; MANUNTA, A. y cols.: "Early endoscopic realignment of post-traumatic posterior urethral disruption". Urology, 57: 628, 2001.

8. GUILLE, F.; CIPOLLA, B.; LEVEQUE, J.M. y cols.: "Early endoscopic realignment of complete traumatic rupture of the posterior urethra". Br. J. Urol., 68: 178, 1991.

9. MELEKOS, M.D.; PANTAZAKOS, A.; DAOUAHER, H. y cols.: "Primary endourologic re-establishment of urethral continuity after disruption of prostatomembranous urethra”. Urology, 39: 135, 1992.

10. GONZÁLEZ, M.; RODRÍGUEZ-RIVERA， J.; SÁNCHEZ, J. y cols.: "Rotura traumática de uretra: tratamiento endourológico precoz". Urol. Integr. Invest., 4: 390, 1998. 